\title{
All printed soft actuators based on ionic liquid/polymer hybrid materials
}

D.M. Correia ${ }^{1,2, *}$, L.C. Fernandes ${ }^{1}$, N. Pereira ${ }^{1,3}$, J.C. Barbosa ${ }^{1,2}$, J.P. Serra ${ }^{1}$, R.S. Pinto ${ }^{1}$, C.M. Costa ${ }^{1,4}$ and S. Lanceros-Mendez ${ }^{5,6, *}$

${ }^{1}$ Centre of Physics, University of Minho, 4710-053 Braga, Portugal

${ }^{2}$ Centre of Chemistry, University of Trás-os-Montes e Alto Douro, 5000-801, Vila Real, Portugal

${ }^{3}$ Algoritmi Center, Minho University, 4800-058 Guimarães, Portugal

${ }^{4}$ Centre of Chemistry, University of Minho 4710-057 Braga, Portugal

${ }^{5}$ BCMaterials, Basque Center for Materials, Applications and Nanostructures, UPV/EHU

Science Park, 48940 Leioa, Spain

${ }^{6}$ Ikerbasque, Basque Foundation for Science, 48009 Bilbao, Spain

\section{*Corresponding authors}

d.correia@fisica.uminho.pt

senentxu.lanceros@bcmaterials.net

\begin{abstract}
Soft actuators are increasingly being required for a variety of application ranging from robotics to biomedicine. This work reports on the development of printable materials for soft actuator applications based on ionic liquids (ILs) and a fluorinated polymer, poly(vinylidene fluoride) (PVDF). ILs sharing the same cation 1-butyl-3methylimidazolium, $[\mathrm{Bmim}]^{+}$and different anions (tricyanomethane, $\left[\mathrm{C}\left(\mathrm{CN}_{3}\right)\right]^{-}$, dicyanamide $\left(\left[\mathrm{N}\left(\mathrm{CN}_{2}^{-}\right)\right]\right)$and thiocyanate) $\left.[\mathrm{SCN}]^{-}\right)$were incorporated into the PVDF polymer matrix at $40 \%$ wt. and processed by direct writing printing technique.

Rheological measurements of the IL/PVDF solutions allowed to stablish a correlation between shear stress and viscosity, being observed a shear thinning behavior. Independently of the IL anion, the inclusion ILs leads to variations in the sample morphology related to the formation of significantly smaller spherulites than in PVDF with well-defined borders and an increase of the electroactive $\beta$ phase content and crystallinity degree of the polymer. The incorporation of the ILs into the PVDF matrix
\end{abstract}


induces a mechanical plasticizing effect. A maximum ionic conductivity of $5.2 \times 10^{-5} \mathrm{~S} / \mathrm{cm}$ has been achieved for the $[\mathrm{Bmim}]\left[\mathrm{N}\left(\mathrm{CN}_{2}\right)\right] / \mathrm{PVDF}$ composite. The potential of the developed printable materials as soft actuators has been experimentally demonstrated and theoretically evaluated, the highest displacement of $1.0 \mathrm{~mm}$ at an applied voltage of 4 Vpp being obtained for [Bmim][SCN]/PVDF. Finally, the implementation of an all printed micro gripper shows the potential of the materials for applications.

Keywords: Soft actuators, Ionic liquids, PVDF, additive manufacturing, printing, hybrid materials 


\section{Introduction}

Additive manufacturing technologies are being increasingly developed and applied in recent years, due to their strong potential in a wide variety of applications, improved integration of materials into devices, the ability to obtain rapid prototypes and solutions in nonconventional shapes, design versatility, compatibility with a wide range of materials, low costs and environmental friendliness [1]. This technologies are based on the gradual accumulation of material to form a 2D or 3D structure previously designed with a computer aided design model [2]. Different types of materials can be printed by these methods, such as polymers [3, 4], ceramics [5, 6], metals [7, 8] or composites [9], some of them with smart and multifunctional characteristics $[10,11]$. Their industrial application areas include aerospace $[12,13]$, automotive [14], food [15, 16], medical [17, 18], construction [19], textile [20] and electronics [21, 22], among others. Additive manufacturing techniques can be divided into seven groups, including binding jetting, directed energy deposition, material extrusion, material jetting, powder bed fusion, sheet lamination and vat photopolymerization [23]. Among the variety of printable materials, smart and multifunctional materials are the focus of increasing attention due to their active response, including sensing and actuation [24].

Smart materials are defined as materials that change their properties in a well-defined, reproducible and stable way, when subjected to an external stimulus [25]. In particular, electroactive polymers (EAPs) are being developed for applications in robotics [26], environmental sensing and remediation [27] or tissue engineering [28], due to their high mechanical flexibility, low density, biocompatibility and easily processability in a variety of shapes [29]. These materials are particularly suited for sensor and actuator applications, due to their high response, versatility, pattern ability, and compatibility with low temperature fabrication processes [24]. Among the few electroactive polymers, poly(vinylidene fluoride (PVDF) and its co-polymers are the most used EAPs for sensor and actuator applications due to their high performance, environmental, mechanical, thermal and chemical stability [30].

PVDF is a semi-crystalline polymer with high dielectric constant and polarity, which has been processes in a large variety of shapes and morphologies [31-34]. There are at least five different chain conformations for the crystalline phase of PVDF, $(\alpha, \beta, \gamma, \delta$ and $\varepsilon)$, being the $\beta$-phase the one with the largest polarity and electroactive response, including piezo-, pyro- and ferroelectricity [35]. 
Piezoelectric actuators show low deformation and mainly high frequency response, requiring typically large driving voltages [36], being therefore limited for some applications. Thus, a new generation of large deformation, low frequency and low voltage actuators are being developed, the most promising approaches being based on ILs introduced in a polymer matrix [36].

ILs can be defined as molten salts, typically composed by an organic cation and an inorganic anion [37]. They are characterized by high ionic conductivity, low vapor pressure, high thermal and electrochemical stability and broad electrochemical window $[38,39]$. By developing IL/polymer hybrids it is possible to combine the properties of both materials, allowing to develop novel materials with tailored mechanical, thermal, electrochemical and functional response, including electromechanical properties [40]. In particular, hybrid materials based on ILs and PVDF have been developed for soft actuators. Studies concerning the effect of the IL type, anion type [41-43], cation size [44], and also the influence of fluorinated matrix [30] in actuators performance have been reported. Thus, the evaluation of the influence of IL cation chain length of different ILs sharing the same anion ([TFSI $]^{-}$) shows that the bending displacement increase with increasing cation chain length, displaying the PVDF/1-propyl-3-imidazolium [PMIM][TFSI] and the PVDF/1-methyl-1-propylpiperidinium [PMPIP][TFSI] the highest bending responses of 5.7 and $6.0 \mathrm{~mm}$, respectively [44]. The comparative study of N,N,N-trimethyl-N-(2-hydroxyethyl) ammonium bis(trifluoromethylsulfonyl)imide $\left(\left[\mathrm{N}_{1112} \mathrm{OH}\right][\mathrm{TFSI}]\right)$ and [EMIM][ESO 4$]$ as active fillers revealed a bending response dependence on IL content more than on IL type [39]. With respect to the influence of anion type for the same cation, [HMIM][Cl] and [HMIM][TFSI], shows the larger bending for the sample with $40 \mathrm{wt} \%$ [HMIM][Cl] content [39]. The influence of the fluorinated matrix type was also addressed upon the incorporation of the IL [Emim][TFSI] into PVDF and its co-polymers being observed a clear matrix type dependence [30].

In this scope, a new interesting and needed approach relies on the development of printable actuators. However, to the best of our knowledge, only a few studies concerning printable IL-polymer based actuators have been reported. Polymer electrolytes based on soluble sulfonated polyimide, comprising the IL [Emim][TFSI] and carbon materials as electron conductive additives (acetylene black, vapor-grown carbon fiber, and Ketjen black) were prepared by layer-by-layer printing [45]. It was demonstrated that the displacement and sped is greatly dependent on the electron-conducting carbon material. 
Actuators with Ketjen black and vapor-grown carbon fiber-based electrodes exhibited the larger displacement at the frequencies exceeding $0.1 \mathrm{~Hz}$ than the actuator based on acetylene black. The printed actuators showed large displacements and a wide potential window up to $3.5 \mathrm{~V}$, being the largest displacement of $\sim 1.7 \mathrm{~mm}$ observed for the sample containing Ketjen black at a frequency of $0.05 \mathrm{~Hz}$ [45].

In the present work, printed samples based on highly conductive ILs from the imidazolium family (1-butyl-3-methylimidazolium tricyanomethane ([Bmim $\left.]\left[\mathrm{C}\left(\mathrm{CN}_{3}\right)\right]\right)$, 1-butyl-3-methylimidazolium dicyanamide $\quad[\mathrm{Bmim}]\left[\mathrm{N}\left(\mathrm{CN}_{2}\right)\right]$ and 1-butyl-3methylimidazolium thiocyanate $([\mathrm{Bmim}][\mathrm{SCN}])$ and PVDF were processed by direct write ink printing technique due to its advantages, such as, simplicity, high efficiency to obtain both simple and complex designs, and scalability, among others [46]. The IL/PVDF printed films morphology, physical-chemical, thermal and mechanical properties were studied, together with their performance as soft actuators and their implementation into a micro gripper device.

\section{Experimental}

\subsection{Materials}

The polymers PVDF 6010 (Mw 300-330 kDa) and sodium carboxymethyl cellulose (CMC) (Mw 250 000) were purchased from Solvay and Aldrich, respectively. The solvent the $N, N$-dimethylformamide (DMF, 99.5\%) was acquired from Merck. The ILs 1-butyl-3-methylimidazolium tricyanomethane $\quad\left([\mathrm{Bmim}]\left[\mathrm{C}\left(\mathrm{CN}_{3}\right)\right]\right), \quad$ 1-butyl-3methylimidazolium dicyanamide $[\mathrm{Bmim}]\left[\mathrm{N}\left(\mathrm{CN}_{2}\right)\right]$ and 1-butyl-3-methylimidazolium thiocyanate $[\mathrm{Bmim}][\mathrm{SCN}]$ were purchased from Iolitec. Table 1 shows the most relevant properties of the ILs.

Table 1. Relevant properties of the selected ILs. Data obtained from the provider.

\begin{tabular}{ccc}
\hline $\mathbf{I} \mathbf{L}$ & $\begin{array}{c}\text { Viscosity } \\
(\mathbf{c P})\end{array}$ & $\begin{array}{c}\text { Ionic conductivity } \\
\left.(\mathbf{m S . c m})^{-\mathbf{1}}\right)\end{array}$ \\
\hline$[\mathrm{Bmim}]\left[\mathrm{C}\left(\mathrm{CN}_{3}\right)\right]$ & $25.7\left(25^{\circ} \mathrm{C}\right)$ & 8.83 \\
{$[\mathrm{Bmim}]\left[\mathrm{N}\left(\mathrm{CN}_{2}\right)\right]$} & 33.4 & 9.54 \\
{$[\mathrm{Bmim}][\mathrm{SCN}]$} & $35.9\left(25^{\circ} \mathrm{C}\right)$ & $8.98\left(30^{\circ} \mathrm{C}\right)$ \\
\hline
\end{tabular}




\subsection{Inks preparation and samples printing}

The IL/PVDF inks comprising the different ILs were prepared as represented in Figure 1 in the following way: first, the ILs were independently dispersed in DMF. Then, PVDF was added to the solution in a 15/85\% w/w ratio (polymer/solvent). Taking into account the previous studies on the compatibilization and miscibility between PVDF and ILs without jellification [47], a ratio of 40/60\% w/w (IL/polymer) was used for each IL (step 1). After complete polymer dissolution, the printing process was carried out in a Single Head 3D Bioprinter (3D Cultures), with a printing speed $=20 \mathrm{~mm} / \mathrm{s}$, using a needle with a diameter $0.5 \mathrm{~mm}$ (Figure 1). Printed samples with a thickness of $\sim 60 \mu \mathrm{m}$ were obtained after drying in a hot plate at $100^{\circ} \mathrm{C}$ (step 2).

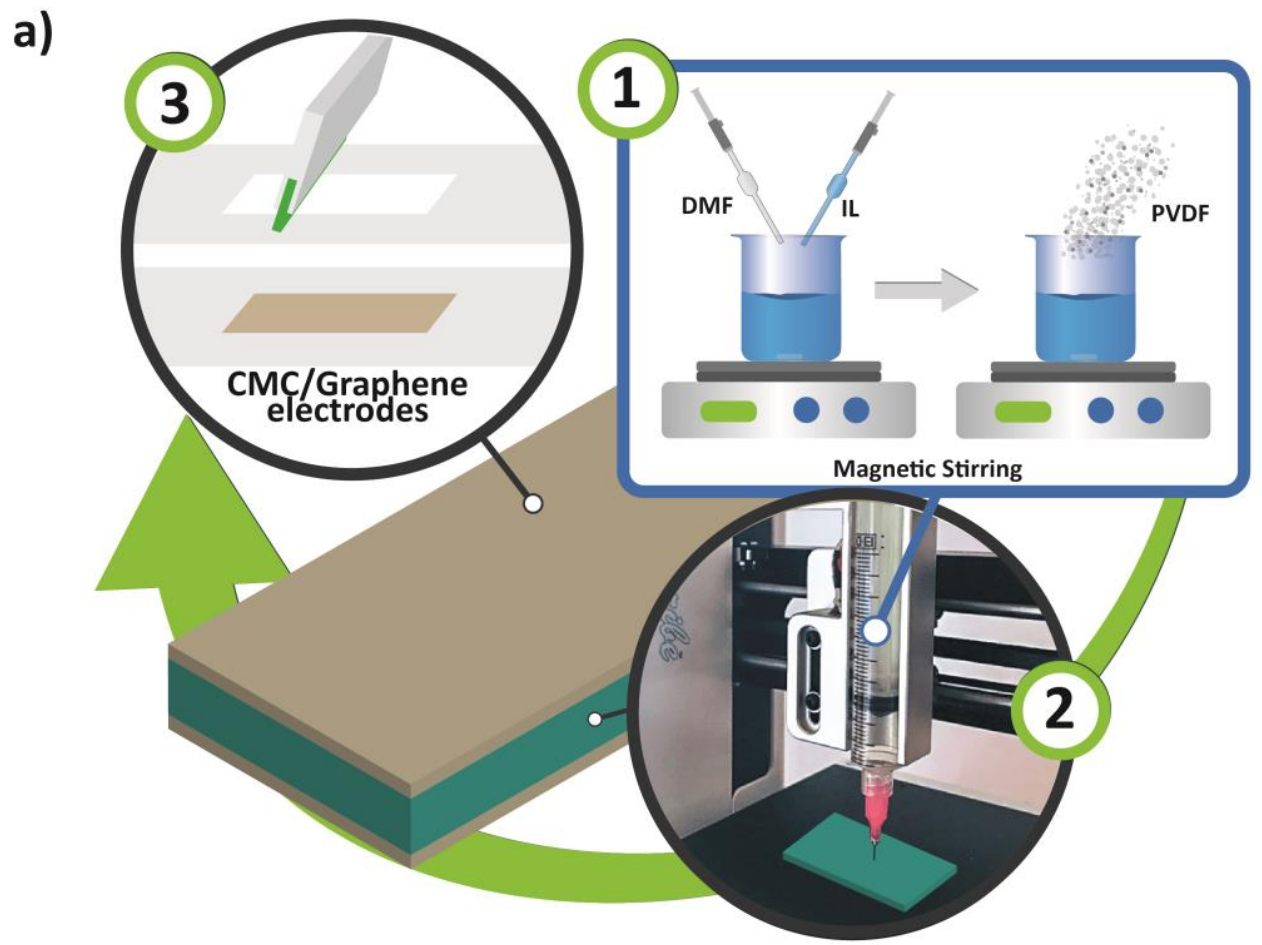

b) 


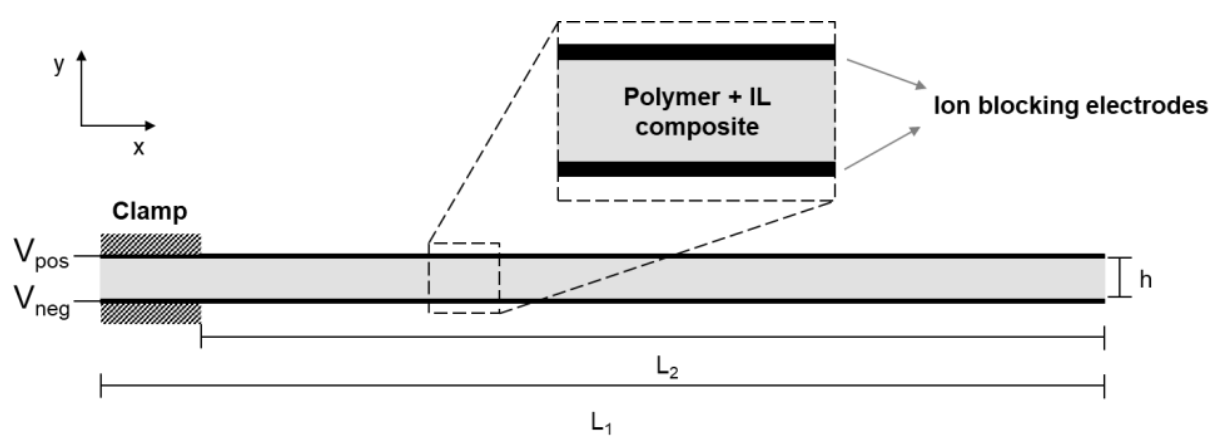

Figure 1. Schematic representation of a) the procedure used for the development of the printed IL/PVDF samples and b) schematic representation of the modeling geometry, with $L_{1}$ and $L_{2}$ representing the actuators total and free length, respectively, and $\mathrm{h}$ the polymer matrix thickness.

\subsection{Actuator fabrication}

For the development of all printed actuators, printed electrodes were deposited into the previously printed IL/polymer samples by screen printing. For the electrodes preparation, $0.45 \mathrm{~g}$ of CMC were dissolved under magnetic stirring in $15 \mathrm{~mL}$ of ethanol. After $5 \mathrm{~min}$, $15 \mathrm{~mL}$ of ultrapure water was added followed by $1.05 \mathrm{~g}$ of PVP and the solution was kept under agitation until complete polymer dissolution. Then, the solution was placed under mechanical stirring and $2.5 \mathrm{~g}$ of graphene nanoplatelets (Graphenest) were carefully added. The final ink solution remained under vigorous agitation for approximately $1 \mathrm{~h}$. The electrodes were printed in both samples surfaces by screen-printing (DSTAR, model DX-305D) with a final thickness of $\sim 24 \mu \mathrm{m}$ (step 3 of Figure 1).

\subsection{Materials characterization}

Rheology tests were carried out in triplicate in a Brookfield DV2T Touch Screen Viscometer using cone-plate geometry with a CPA- $52 \mathrm{Z}$ cone $\left(3^{\circ}\right.$ cone angle, $1.2 \mathrm{~cm}$ cone radius) with shear rates of 2 to $40 \mathrm{~s}^{-1}$ at $25^{\circ} \mathrm{C}$.

Scanning Electronic Microscopy (SEM) was performed with a NanoSem - FEI Nova 200 (FEG/SEM). Prior to the measurements, samples were coated with a conductive gold layer by magnetron sputtering with a Polaron SC502 apparatus.

Fourier transform infrared (FTIR) spectroscopy measurements were carried out in ATR mode using a Jasco FT/IR-4100 apparatus at room temperature, in the frequency range 
from 4000 to $600 \mathrm{~cm}^{-1}$. The quantification of the electroactive phase content of the polymer was performed after Equation 1 [48]:

$$
F(\beta)=\frac{A_{\beta}}{\left(\frac{K_{\beta}}{K_{\alpha}}\right) A_{\alpha}+A_{\beta}}
$$

where the absorbances $(A)$ of the $\alpha$ and $\beta$ phases are calculated from the 766 and $840 \mathrm{~cm}^{-1}$ peaks, respectively, and $K_{766}$ and $K_{840}$ are the corresponding absorption coefficients, 6.1 $\times 10^{4}$ and $7.7 \times 10^{4} \mathrm{~cm}^{2} \mathrm{~mol}^{-1}$, respectively [48].

The thermal properties of the IL/PVDF composites were evaluated by Differential Scanning Calorimetry (DSC) performed with a Metler Toledo DSC 822 apparatus, using a heating rate of $10^{\circ} \mathrm{C} / \mathrm{min}$ under nitrogen atmosphere. The degree of crystallinity of the samples $\left(\chi_{c}\right)$ was calculated following Equation 2 [48]:

$$
\chi_{c}=\frac{\Delta H}{x \Delta H_{\alpha}+y \Delta H_{\beta}}
$$

where the melting enthalpy of PVDF is represented by $\Delta H, \Delta H_{\alpha}$ is the melting enthalpy of the $\alpha$ phase $\left(93.07 \mathrm{Jg}^{-1}\right)$, and $\Delta H_{\beta}$ of the $\beta$ phase $\left(103.4 \mathrm{Jg}^{-1}\right)$ [48]. The proportions of each phase ( $\alpha$ and $\beta$, calculated from the FTIR data) are represented by $x$ and $y$, respectively.

The thermal degradation of the samples was evaluated by thermogravimetric analysis (TGA) using a Mettler Toledo SDTA851 set up in the temperature range 25 to $800{ }^{\circ} \mathrm{C}$. A heating rate of $10{ }^{\circ} \mathrm{C} / \mathrm{min}$ under nitrogen atmosphere was used for the measurements.

The mechanical properties of the samples were evaluated at room temperature under tensile stress-strain experiments using a Linkam Scientific Instruments TST 360 with a load cell of $200 \mathrm{~N}$ at a constant uniaxial deformation of $10 \mu \mathrm{m} \mathrm{s}^{-1}$.

The ionic conductivity of the samples was determined using the complex plane impedance technique in an Autolab PGSTAT-12/30 instrument, between 15 and $100^{\circ} \mathrm{C}$. The samples were placed between two $10 \mathrm{~mm}$ diameter steel electrodes in a heating chamber with Buchi oven. The ionic conductivity $\left(\sigma_{i}\right)$ was calculated using Equation 3: 


$$
\sigma_{i}=\frac{d}{R_{b} \times A}
$$

where $R_{b}$ is the bulk resistance, $d$ is the thickness and $A$ is the area of the electrodes.

\subsection{Electromechanical characterization of the actuator}

The displacement of the IL/PVDF printed actuator active materials were first evaluated with deposited (Polaron SC502) gold electrodes with dimensions of $12 \mathrm{~mm} \times 2 \mathrm{~mm}$ in both sides of the samples. Measurements were carried out, using an Agilent 33220A function generator and an oscilloscope PicoScope 4227, by applying a square wave signal with an applied voltage of $4 \mathrm{Vpp}$ at a frequency of $100 \mathrm{mHz}$. In a similar way, the performance of the all printed bending actuators were evaluated under the same conditions but in DC mode. Printing actuators with a total thickness (active layer and electrodes) of $\sim 55.2 \mu \mathrm{m}$ for $[\mathrm{Bmim}]\left[\mathrm{N}\left(\mathrm{CN}_{2}\right)\right] / \mathrm{PVDF}, 56.8 \mu \mathrm{m}$ for $[\mathrm{Bmim}][\mathrm{SCN}] / \mathrm{PVDF}$ and $41 \mu \mathrm{m}$ for $[\mathrm{Bmim}]\left[\mathrm{C}\left(\mathrm{CN}_{3}\right)\right] / \mathrm{PVDF}$ were evaluated.

The micro gripper was evaluated by combining two $[\mathrm{Bmim}]\left[\mathrm{N}\left(\mathrm{CN}_{2}\right)\right] / \mathrm{PVDF}$ printed actuators with the dimension of $30 \mathrm{~mm}$ x $5 \mathrm{~mm}$. The two films were separated by a $3 \mathrm{~mm}$ 3D printed PLA (Colorfila, $2.85 \mathrm{~mm}( \pm 0.05 \mathrm{~mm})$ ) spacer glued to aluminum tape for electric contact between the power supply and the $[\mathrm{Bmim}]\left[\mathrm{N}\left(\mathrm{CN}_{2}\right)\right] / \mathrm{PVDF}$ films. The micro gripper was supplied with a controlled voltage from a Keithley 2400 sourcemeter.

\section{Numerical simulations of the actuator}

The DC displacement of the actuators was simulated based on the Poisson-Nernst-Planck equations by the finite-element method, according to the following equations $[49,50]$ :

Nernst-Plank equation

$$
\frac{\partial C_{i}}{d t}+\nabla \cdot\left(-D_{i} \nabla C_{i}-z_{i} \mu_{i} C_{i} \mathrm{~F} \nabla \phi\right)=0
$$

Poisson's equation

$$
-\nabla^{2} \phi=\frac{\rho}{\varepsilon} ; \rho=F\left(C-C_{a}\right)
$$

Solid Mechanics

$$
-\nabla \cdot \sigma_{f}=\mathbf{F} ; \mathbf{F}=f(\rho)=\left(\frac{A}{F} \rho+\frac{B}{F^{2}} \rho^{2}\right) \hat{x}
$$


Where $C$ is the ion concentration ( $C$ for the cation and $C_{a}$ for the anion), $D$ the ionic diffusion coefficient, $z$ the charge and $\mu$ the mobility of the ions [51], $\rho$ the charge density, $F$ the Faradays constant and $\varepsilon$ the dielectric permittivity. Finally, $A$ and $B$ are empirical coefficients [49].

A schematic representation of the model geometry is presented in Figure 1b, being a simple 2D geometry of the cross section of the actuator, composed of: the actuators total length $\left(L_{1}\right)$, the clamped area, the free length $\left(\mathrm{L}_{2}\right)$, the polymer matrix thickness and the electrodes.

The electrode thickness was negligible when compared to the actuator thickness as it is considered that ion transfer does not occur into the electrodes during bending. The molecular weight of the ILs $[\mathrm{Bmim}][\mathrm{SCN}]$ and $[\mathrm{Bmim}]\left[\mathrm{C}\left(\mathrm{CN}_{3}\right)\right]$ were considered, respectively, 562.6 and 229.28 according to the manufacturer (Iolitec) information. The values for the ILs simulation constants were as follows: effective dielectric permittivity $=2 \times 10^{-3} \mathrm{~F} \cdot \mathrm{m}^{-1}$, this high value has been theoretically justified based on the high surface area of the electrodes $[49,52,53]$, but it is to notice that it can be also explained by the highly conductive and dissipative character of the hybrid materials, related to the IL cation and anion migration contributions within the material [54-57]; diffusion constant $=1 \times 10^{-13} \mathrm{~m}^{2} \cdot \mathrm{s}^{-1}$ for the $[\mathrm{Bmim}]^{+}$cation and $2 \times 10^{-13} \mathrm{~m}^{2} \cdot \mathrm{s}^{-1}$ for the $[\mathrm{SCN}]^{-}$and $1.5 \times 10^{-13}$ $\mathrm{m}^{2} \cdot \mathrm{s}^{-1}$ for the $\left[\mathrm{C}\left(\mathrm{CN}_{3}\right)\right]^{-}$anions, as it is dependent on the ion size and geometry. The cations diffusion being smaller for the anions as they are typically larger in size[50]. Further, the anion shows smaller diffusion also due their nonlinear geometry. The electrodes are characterized by and electrical resistivity of $0.04394 \Omega \mathrm{m}$. The model was solved for a time-dependent scenario under an applied DC voltage of $4 \mathrm{~V}$.

\section{Results and discussion}

\subsection{Rheological and morphological analysis}

The rheological properties of the IL/PVDF solutions comprising the different ILs where evaluated, as the rheological behavior of the inks determines the 3D printing procedure and conditions [58]. It is to notice that the electrostatic interactions between the IL and the polymer can affect the segmental dynamics of the polymer chain in the IL/polymer solutions [59], leading to nonlinear rheological properties resulting from the viscosity 
increase of the polymer solution [59]. Further, this interaction is particularly relevant in the case of PVDF due to its polar characteristics [48]. Figure 2a shows that the shear stress increases with increasing shear rate for all IL/PVDF samples, being independent of the IL type. It is also observed a correlation between shear stress and the viscosity of the ILs, the solutions showing a shear thinning behavior characteristic of non-Newtonian fluids and time-independent response.

The different IL/PVDF solutions do not show any thixotropic behavior and the data can be fitted by the Herschel-Bulkley law (Figure 2a) which is the constitutive equation describing yield stress materials [60]:

$$
\tau=\tau_{y}+K \dot{\gamma}^{n}
$$

where $\tau_{y}$ is the yield stress beyond which the material flows with a shear rate $\gamma$ in a nonNewtonian fashion, characterized by a thinning index $n$ and a constant K [60]. Table 2 shows the different values obtained by fitting of the Herschel Bulkley equation to the data presented in $2 \mathrm{a}$.

Table 2 - Yield stress, $\tau_{y}$, thinning index, $\mathrm{n}$, and constant $K$ values obtained from the fitting of the Herschel-Bulkley equation to the data presented in Figure 2a.

\begin{tabular}{|c|c|c|c|}
\hline IL/PVDF & $\boldsymbol{\tau}_{\boldsymbol{y}}(\boldsymbol{P a})$ & $\boldsymbol{K}$ & $\boldsymbol{n}$ \\
\hline$[\mathrm{Bmim}]\left[\mathrm{C}\left(\mathrm{CN}_{3}\right)\right] / \mathrm{PVDF}$ & $8.4 \pm 1.9$ & $74 \pm 18$ & $0.5 \pm 0.05$ \\
\hline$[\mathrm{Bmim}]\left[\mathrm{N}\left(\mathrm{CN}_{2}\right)\right] / \mathrm{PVDF}$ & $4.9 \pm 1.7$ & $32 \pm 2.9$ & $0.7 \pm 0.02$ \\
\hline$[\mathrm{Bmim}][\mathrm{SCN}] / \mathrm{PVDF}$ & $10 \pm 1.1$ & $38 \pm 5.0$ & $0.7 \pm 0.03$ \\
\hline
\end{tabular}

The different yield stress values are ascribed to the different IL viscosities that affect the microstructural arrangement of the solution for stresses above the yield stress, leading to a flow with pseudoplastic fluid [61]. The thinning index $n$ for the IL/PVDF solutions is below 1 confirming the non-Newtonian flow behavior [62].

The morphology of the IL/PVDF printed composites was evaluated by SEM and the surface and cross-section images are shown in Figure 2.

Neat PVDF films obtained by doctor blade at temperatures above $100{ }^{\circ} \mathrm{C}$ present a homogenous and compact spherulitic structure with the absence of pores [63]. The same 
behavior is observed for neat PVDF obtained by direct-ink printing, indicating that the printing process does not induces morphological modifications in the PVDF films.
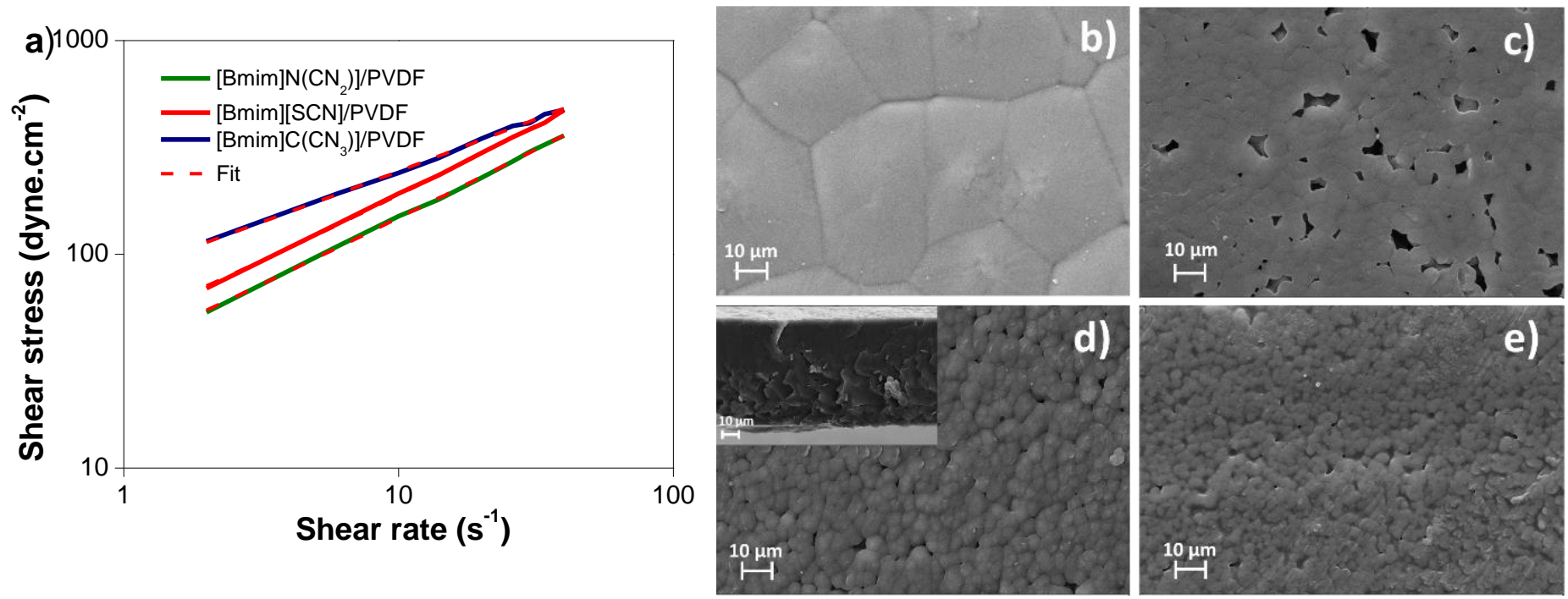

Figure 2. a) Log shear/stress for the different IL/PVDF solutions. b-e: Representative surface SEM images of the samples obtained by direct-write ink printing: $b$ ) neat PVDF film, c) $[\mathrm{Bmim}]\left[\mathrm{N}\left(\mathrm{CN}_{2}\right)\right] / \mathrm{PVDF}$; ) $[\mathrm{Bmim}][\mathrm{SCN}] / \mathrm{PVDF}$ (cross section presented in the inset) and e) $[\mathrm{Bmim}]\left[\mathrm{C}\left(\mathrm{CN}_{3}\right)\right] / \mathrm{PVDF}$ films.

With respect to the IL/PVDF composites SEM images, Figure 2c-2e, independently of the anion type, the incorporation of ILs into the PVDF matrix leads to the formation of significantly smaller spherulites than in pristine PVDF and with well-defined borders. This fact is indicative that the ILs acts as nucleating agent of polymer crystallization during solvent evaporation, leading to the formation of a higher number of simultaneously growing spherulites [64]. As a result, a less compact structure with the presence of voids is obtained.

\subsection{Polymer phase content, thermal and mechanical properties}

The influence of anion type into the polymer phase content of the IL/PVDF samples was evaluated by FTIR-ATR measurements. Figure 3a shows that, independently of the anion type, the main PVDF characteristic absorption bands are similar for all hybrid samples. 

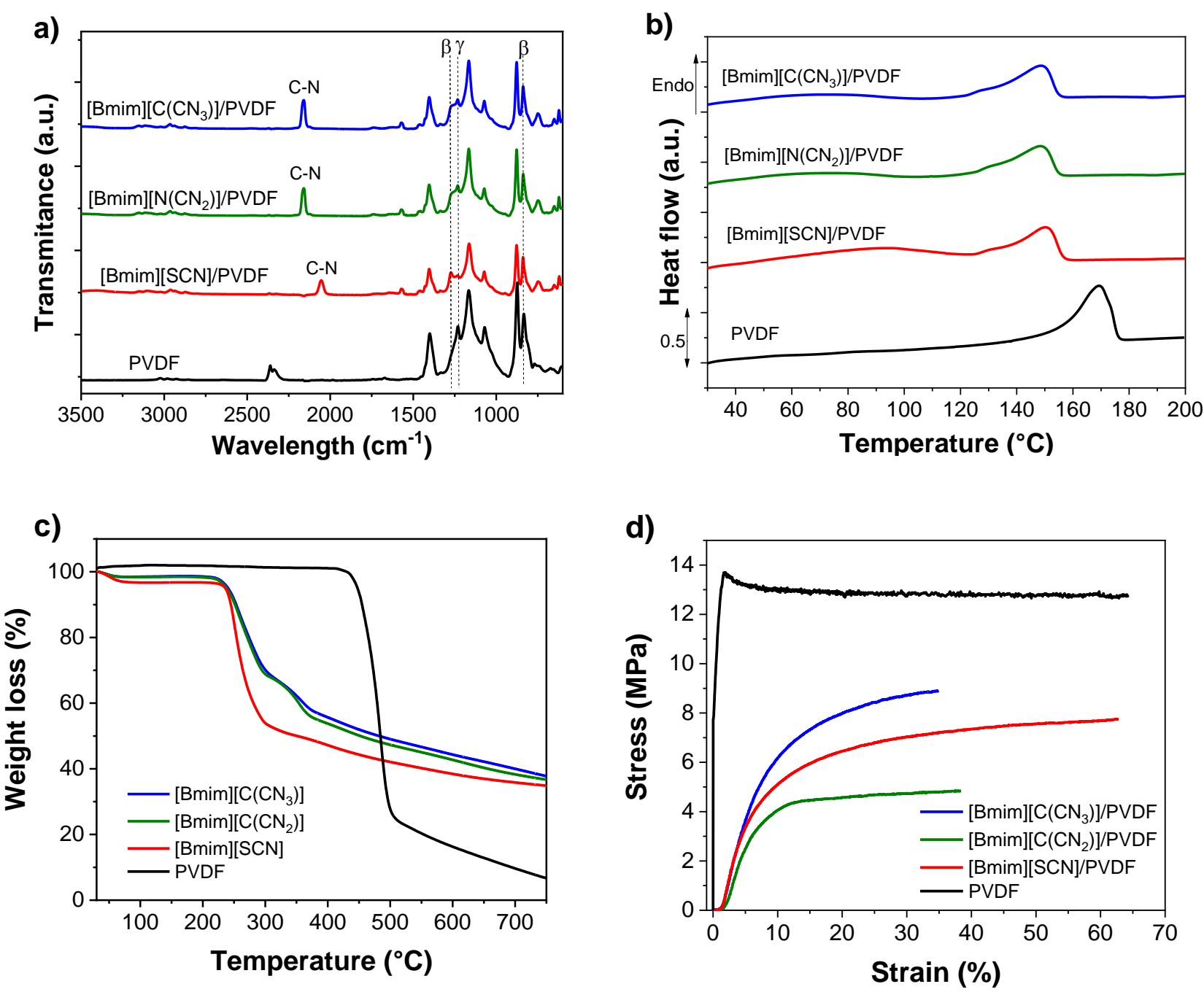

Figure 3. a) FTIR-ATR spectra, (b) DSC scans, (c) thermogravimetric curves and (d) stress-strain curves for pristine PVDF and printed hybrid samples with different ILs.

PVDF crystallizes mainly in the electroactive $\beta$ phase for solvent evaporation temperatures lower than $100{ }^{\circ} \mathrm{C}$ [32]. As it is observed in FTIR spectra of Figure 3, the electroactive $\beta$ phase is identified by the presence of the absorption bands at $840 \mathrm{~cm}^{-1}$ and $1275 \mathrm{~cm}^{-1}$ in all samples being an indication that the main determining factor for polymer crystallization is the processing temperature. Additionally, also a small amount of $\gamma$ phase is identified at $1232 \mathrm{~cm}^{-1}$ [65].

The IL characteristic absorption bands are also identified in the FTIR-ATR spectra. ILs sharing the same cation of the imidazolium family present an absorption band at $840 \mathrm{~cm}^{-}$ ${ }^{1}$ characteristic of the $\mathrm{NC}(\mathrm{H}) \mathrm{N}$ and $\mathrm{CCH}$ groups of the imidazolium ring [66]. However, due to the absence of other characteristics imidazolium absorption bands, and additionally 
to the relative low intensity of this IL stretching vibration band [66], the absorption band at $840 \mathrm{~cm}^{-1}$ is mostly ascribed to the electroactive $\beta$ phase of PVDF. The different ILs can be also identified by the anion characteristic absorption bands. The $\mathrm{C}-\mathrm{N}$ stretching vibration characteristic of the $\left[\mathrm{N}\left(\mathrm{CN}_{2}\right)\right]^{-}$and $\left[\mathrm{C}\left(\mathrm{CN}_{3}\right)\right]^{-}$anions is observed at $2164 \mathrm{~cm}^{-1}$ [67]. For the [SCN $]^{-}$anion, a single peak appears at $\sim 2054 \mathrm{~cm}^{-1}$, which is assigned to the C-N vibration mode [67].

The quantification of the electroactive $\beta$ phase was performed using the Equation 1 and are presented in Table 3. Independently of the anion type and, even when the crystallization phase is mainly determined by the processing temperature [63], as discussed before, the presence of the ILs leads to an increase of the $\beta$ phase content with respect to pristine PVDF from $67 \%$ to $82 \%$. This fact demonstrates that the incorporation of the ILs into the PVDF polymer matrix promotes electrostatic interactions (ion-dipole) between the ILs anions and cations and the dipoles of the PVDF chain, supporting the PVDF crystallization into the all-trans $\beta$ phase conformation [44]. Additionally, it is also to notice that no significant differences are observed in the $\beta$ phase content for the different ILs, being therefore independent of the anion type. The highest $\beta$ phase content $(82 \%)$ is observed for [Bmim][SCN]/PVDF printed films. The similarity of the anions does not lead to significant differences between the interaction of the cation with the $\mathrm{CF}_{2}$ PVDF groups or between the different anions with the $\mathrm{CH}_{2}$ groups of the PVDF polymer chain.

The thermal properties and degree of crystallinity of the IL/PVDF samples were evaluated by DSC, as presented in Figure 3b.

All IL/PVDF samples are characterized by the endothermic peak typical of PVDF (Figure 3b), which presents an endothermic peak between 150 and $170{ }^{\circ} \mathrm{C}[44,68]$. The melting of IL/PVDF composites occurs at lower temperatures $\left(148^{\circ} \mathrm{C}\right)$, when compared with neat PVDF, as a result of the crystalline phase destabilization attributed to the electrostatic interactions between the different ILs and the PVDF chain[47, 69].

The effect of the anion type on the degree of crystallinity was quantitatively evaluated by Equation 2 on the basis of the DSC data (Table 3).

Whereas PVDF shows a degree of crystallinity of 50\%, similar to the values reported for PVDF films obtained by doctor blade (52\%) [44], a decrease in the degree of crystallinity upon ILs incorporation is observed, with no significant differences between the different printed IL/PVDF samples. The observed decrease in crystallinity is attributed to the 
mentioned IL-PVDF chain interactions during the crystallization process, promoting the decrease in the spherulites lamellar size [47].

Table 3. Electroactive $\beta$ phase content and degree of crystallinity for the different IL/PVDF printed composites.

\begin{tabular}{|c|c|c|c|c|}
\hline IL/PVDF & $\begin{array}{c}\boldsymbol{\beta} \text {-phase } \\
\mathbf{\pm 3} \%\end{array}$ & $\begin{array}{c}\text { Crystallinity } \\
\text { degree } \mathbf{\pm 2} \%\end{array}$ & $\begin{array}{c}\text { Young } \\
\text { Modulus } \mathbf{\pm 1 0} \\
\mathbf{( M P a}\end{array}$ & $\begin{array}{c}\text { Yield } \\
\text { Strength } \mathbf{\pm} \\
\mathbf{0 . 5}(\mathbf{M P a})\end{array}$ \\
\hline $\mathrm{PVDF}$ & 67 & 50 & 1840 & 125 \\
\hline$[\mathrm{Bmim}]\left[\mathrm{C}\left(\mathrm{CN}_{3}\right)\right] / \mathrm{PVDF}$ & 79 & 33 & 91.3 & 4.56 \\
\hline$[\mathrm{Bmim}]\left[\mathrm{N}_{2}\left(\mathrm{CN}_{2}\right)\right]$ PVDF & 78 & 31 & 79.3 & 2.53 \\
\hline$[\mathrm{Bmim}][\mathrm{SCN}] / \mathrm{PVDF}$ & 82 & 28 & 89.4 & 3.64 \\
\hline
\end{tabular}

The thermal properties of the composites were further evaluated by thermogravimetric analysis (Figure 3c). PVDF shows a TGA thermogram with just a single degradation step with the initial degradation at a $\mathrm{T}_{\text {onset }}$ of $\sim 450{ }^{\circ} \mathrm{C}$, related with the scission of the carbon-fluoride and carbon-hydrogen bonds scission [70]. On the other hand, IL/PVDF samples show two degradation steps, independently of the IL anion type. The first thermal degradation step occurs between $25^{\circ} \mathrm{C}$ and $100^{\circ} \mathrm{C}$ being related to the water loss due to the hygroscopic characteristic of the imidazolium based ILs [71]. For the $[\mathrm{Bmim}]\left[\mathrm{C}\left(\mathrm{CN}_{3}\right)\right] / \mathrm{PVDF}$ and $[\mathrm{Bmim}]\left[\mathrm{N}\left(\mathrm{CN}_{2}\right)\right] / \mathrm{PVDF}$ samples, a second degradation peak ranging from $230{ }^{\circ} \mathrm{C}$ to $236{ }^{\circ} \mathrm{C}$ is observed, corresponding to the [Bmim] $\left[\mathrm{N}\left(\mathrm{CN}_{2}\right)\right]$ and $[\mathrm{Bmim}]\left[\mathrm{C}\left(\mathrm{CN}_{3}\right)\right]$ ILs [72].

The last weight loss is similar for all hybrid materials, it occurs between $\sim 300{ }^{\circ} \mathrm{C}$ and $400^{\circ} \mathrm{C}$ and is attributed to the degradation of PVDF. Thus, independently of the anion type, the inclusion of the ILs into the PVDF matrix induces a relevant decrease in the thermal stability, attributed to the catalytic effect of the anions and cations of the IL on the degradation reaction of PVDF. It is to notice that the inclusion of the IL [Bmim] $[\mathrm{SCN}]$ does not affect the thermal stability of PVDF, occurring the thermal degradation of the IL and PVDF in one step.

The mechanical properties of the IL/PVDF composites as a function of anion type were evaluated by tensile measurements. The stress vs strain curves are presented in Figure 3d and the Young Modulus, determined from the linear regime at 3\% of elongation in the elastic region by the tangent method, is presented in Table 3. 
Neat PVDF films exhibit a mechanical behavior typical of a thermoplastic polymer as reported in [44] and the same occurs for the IL/PVDF samples. All hybrid samples are characterized by a plasticizing effect attributed to the presence of ILs, that reduces Young modulus and yield stress.

From the stress vs strain measurements presented in Figure 3d), the Young modulus and yield strength are obtained (Table 3). The IL acts as a plasticizing agent, decreasing the Young Modulus and the tensile strength with respect to PVDF [44], being no significative the differences observed for the different samples sharing the same cation.

\subsection{Ionic Conductivity}

The ionic conductivity of the IL/PVDF samples was evaluated by impedance spectroscopy measurements. The Nyquist profiles obtained at room temperature are shown in Figure 4a, where it is observed a linear region with increasing frequency, being this linear region associated with the diffusion of IL cations and anions. The resistance values follow the order: $[\mathrm{Bmim}][\mathrm{SCN}]>[\mathrm{Bmim}]\left[\mathrm{N}\left(\mathrm{CN}_{2}\right)\right]>[\mathrm{Bmim}]\left[\mathrm{C}\left(\mathrm{CN}_{3}\right)\right]$ indicating that anion sizes and high IL viscosity hinder the mobility of the ionic charges. Thus, as presented in Table 1, the IL [Bmim][SCN] shows the highest viscosity value ( $35.9 \mathrm{cP})$. From Figure $\mathbf{4 b}$ it is observed that independently of the anion type, the resistance of the samples decreases with increasing temperature in the printed composites due to enhancement of segmental motion of the PVDF polymer chains and increase of ionic mobility [73]. From Figure $\mathbf{4 b}$ and using Equation 3, the ionic conductivity of the samples has been determined. 

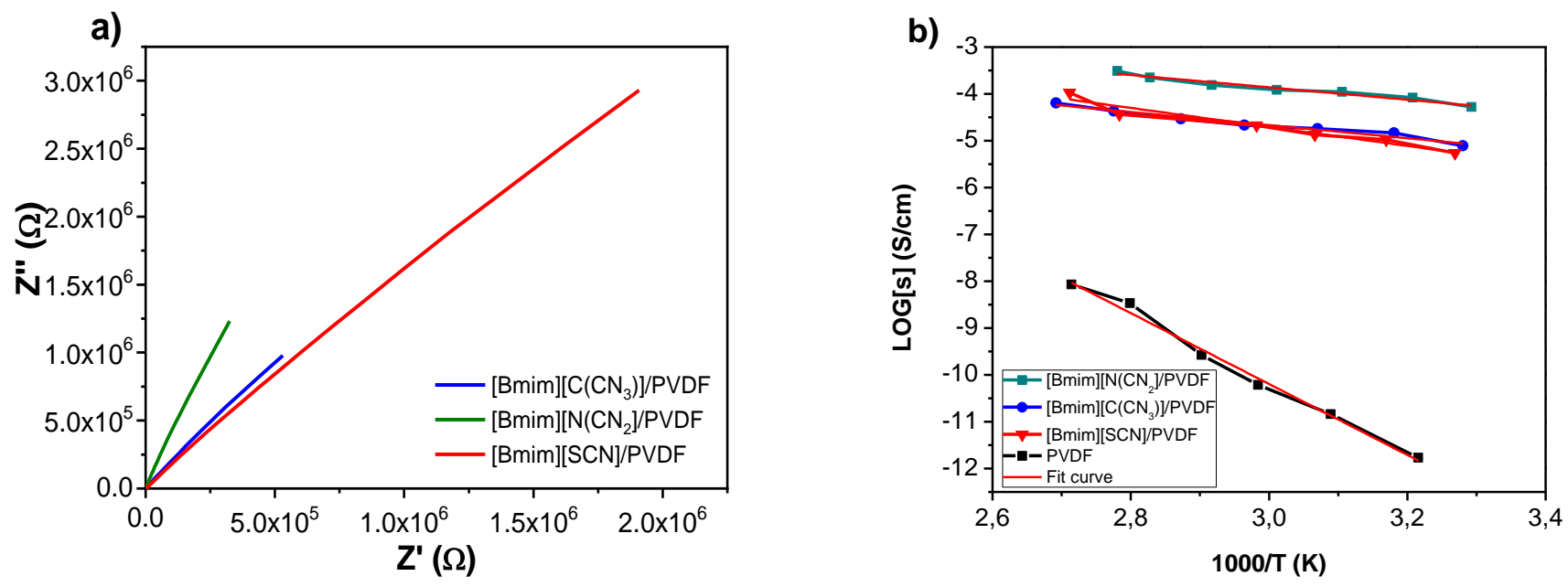

Figure 4. a) Nyquist plot of the IL/PVDF samples at room temperature and b) Arrhenius plots for the ionic conductivities of the same samples.

The ionic conductivity value of the IL/PVDF films is due to the inclusion of the IL, leading to an increase of the number and mobility of charge carries (cations and anions). Independently of the IL type, the ionic conductivity increases with respect to neat PVDF in up to six orders of magnitude.

The value of the conductivity as a function of temperature follows the Arrhenius equation and the activation energy is obtained through equation 5:

$$
\sigma=\sigma_{0} \exp \left(-E_{a} / R T\right)
$$

where $\sigma$ is the ionic conductivity, $\sigma_{0}, E_{a}, R$ and $T$ are the pre-exponential factor, the apparent activation energy for ion transport, the gas constant $\left(8.314 \mathrm{~J} \mathrm{~K}^{-1} \mathrm{~mol}^{-1}\right)$ and the temperature, respectively.

Table 4. Activation energy and room temperature (RT) ionic conductivity of the printed samples.

\begin{tabular}{|l|c|c|}
\hline Sample & Activation energy $\left(\mathbf{k J . m o l} \mathbf{~}^{\mathbf{1}}\right)$ & $\begin{array}{c}\text { RT Ionic conductivity (S } \\
\left.\mathbf{c m}^{\mathbf{- 1}}\right)\end{array}$ \\
\hline PVDF & 63 & $6.8 \times 10^{-11}$ \\
\hline$[\mathrm{Bmim}]\left[\mathrm{C}\left(\mathrm{CN}_{3}\right)\right] / \mathrm{PVDF}$ & 11.63 & $6.0 \times 10^{-6}$ \\
\hline$[\mathrm{Bmim}]\left[\mathrm{N}\left(\mathrm{CN}_{2}\right)\right] / \mathrm{PVDF}$ & 10.98 & $5.2 \times 10^{-5}$ \\
\hline$[\mathrm{Bmim}][\mathrm{SCN}] / \mathrm{PVDF}$ & 16.85 & $5.4 \times 10^{-6}$ \\
\hline
\end{tabular}


The activation energy $\left(E_{a}\right)$ of the samples and the ionic conductivity is shown in Table 4. The ionic conductivity is higher for $[\mathrm{Bmim}]\left[\mathrm{N}\left(\mathrm{CN}_{2}\right)\right] / \mathrm{PVDF}$ composite $\left(5.2 \times 10^{-5} \mathrm{~S} / \mathrm{cm}\right.$ vs $1.6 \times 10^{-5} \mathrm{~S} \mathrm{~cm}^{-1}$ for the same composite obtained by the doctor blade technique), resulting from the higher ions mobility into the amorphous phase of PVDF matrix due to both the high conductivity of $[\mathrm{Bmim}]\left[\mathrm{N}\left(\mathrm{CN}_{2}\right)\right]$ (Table 1) and the lower crystallinity degree of the sample. From Figure $4 \mathrm{~b}$ it is also observed an ionic conductive anion dependence, being the lowest conductivity value of $6.0 \times 10^{-6} \mathrm{~S} \mathrm{~cm}^{-1}$ obtained for $[\mathrm{Bmim}]\left[\mathrm{C}\left(\mathrm{CN}_{3}\right)\right] / \mathrm{PVDF}$ composite.

\subsection{Electromechanical measurements}

The bending response of the prepared samples for soft actuator applications has been assessed by electromechanical measurements in both DC and AC modes at applied voltages of $4 \mathrm{~V}$ and $4 \mathrm{~V}_{\mathrm{pp}}$, respectively, the latter at a frequency of $100 \mathrm{mHz}$. It is to notice that the maximum AC voltages are half the applied DC voltage. Figure 5 shows the bending tip displacement of the fully printed actuators in both modes, the bending behavior depending on the applied voltage mode.
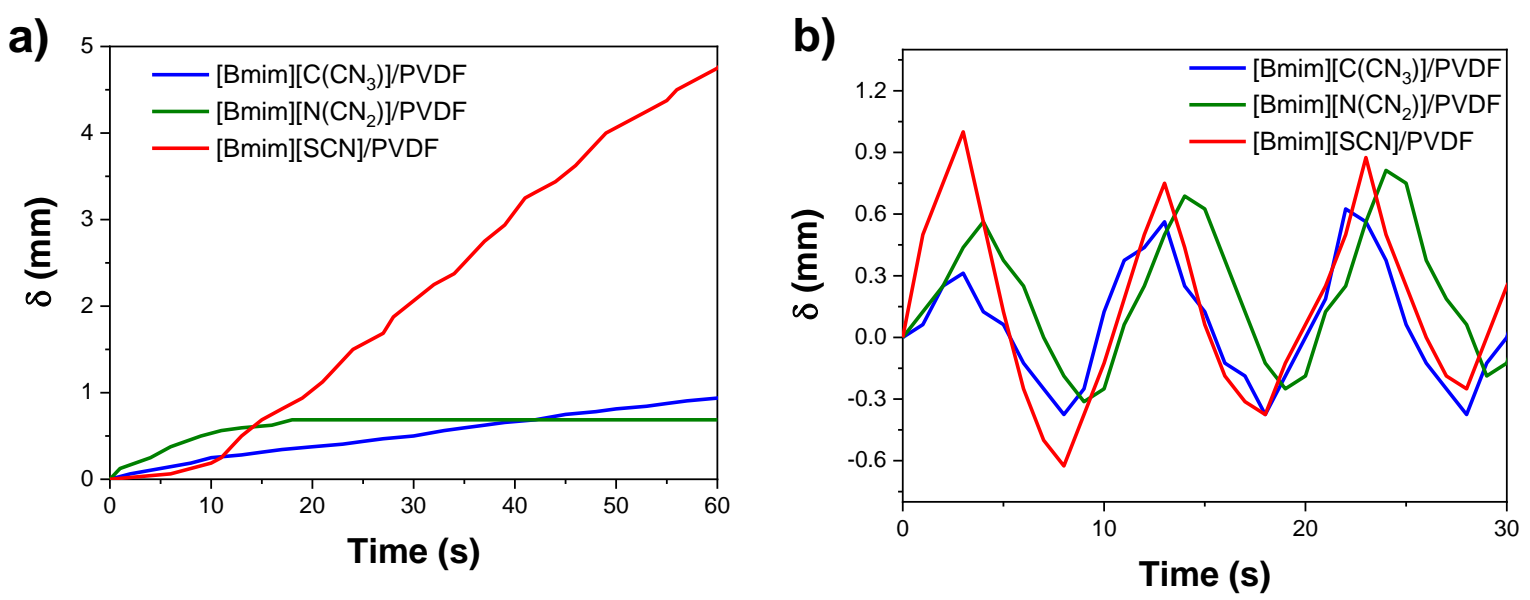

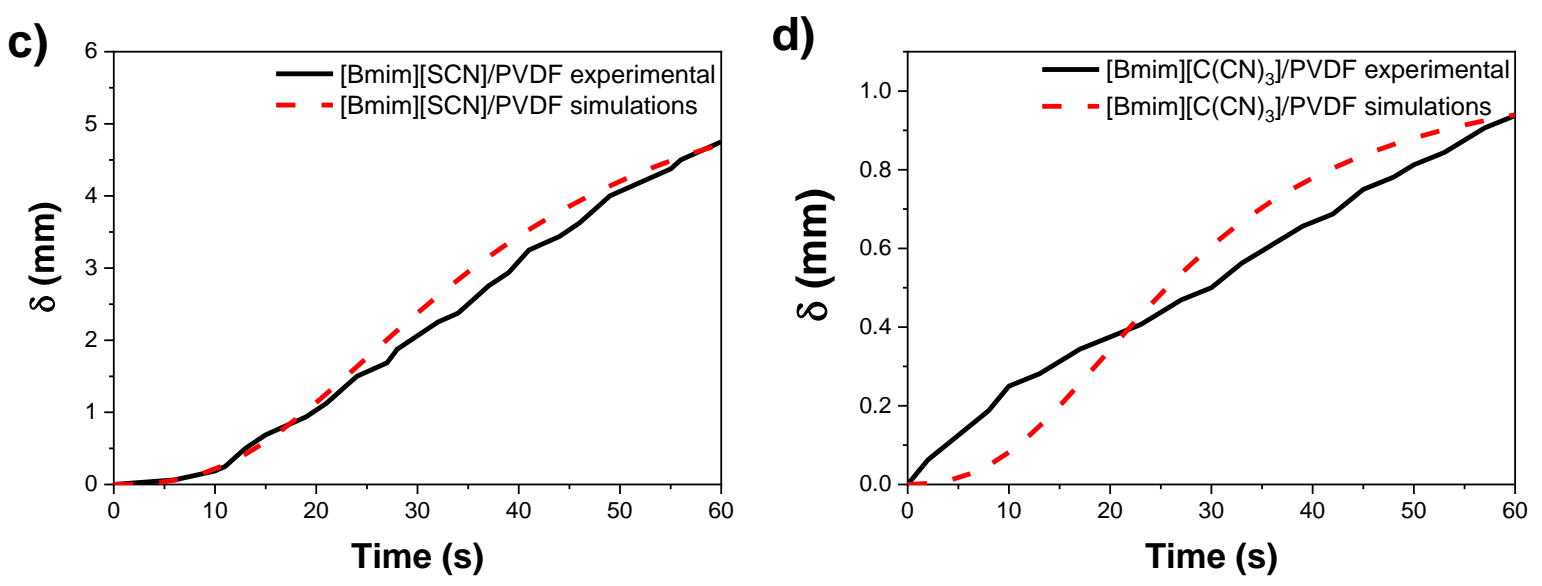

Figure 5. Displacement of the different IL/PVDF fully printed actuators under an: a) DC field at an applied voltage of $4 \mathrm{~V}$ and b) AC field at an applied voltage of $4 \mathrm{~V}_{\mathrm{pp}}$ at 100 mHz. $\mathrm{c}$ and d) Measured and modeled tip displacements for c) [Bmim][SCN]/PVDF (c) and $[\mathrm{Bmim}]\left[\mathrm{C}\left(\mathrm{CN}_{3}\right)\right] / \mathrm{PVDF}(\mathrm{d})$ in an DC field at an applied voltage of $4 \mathrm{~V}$.

In DC mode (Figure 5a), the $[\mathrm{Bmim}][\mathrm{SCN}] / \mathrm{PVDF}$ sample developed the largest displacement when compared to the other composites, being $4.75 \mathrm{~mm}$ during the first 60 s. The bending motion when an AC field is applied is shown in Figure 5b. A nonsymmetrical behavior is observed, which is similar for all samples. The highest displacement has been observed for the sample comprising the IL [Bmim] [SCN] $(1.0$ $\mathrm{mm}$ ) (Figure 6a and supplementary video S1) followed by $[\mathrm{Bmim}]\left[\mathrm{N}\left(\mathrm{CN}_{2}\right)\right](0.9 \mathrm{~mm})$ and $[\mathrm{Bmim}]\left[\mathrm{C}\left(\mathrm{CN}_{3}\right)\right](0.6 \mathrm{~mm})$. This trend is attributed to the higher ionic conductivity of the $[\mathrm{Bmim}][\mathrm{SCN}]$ followed by the $[\mathrm{Bmim}]\left[\mathrm{N}\left(\mathrm{CN}_{2}\right)\right]$ and $[\mathrm{Bmim}]\left[\mathrm{C}\left(\mathrm{CN}_{3}\right)\right]$ which favoured the cation and anion movement into the PVDF matrix. With the application of the electrical field, the IL ions tend to diffuse within the PVDF matrix, to the positive and negative (cations and anions, respectively) side of the electrode layers. This fact results in the accumulation of the cations and anions close to the electrodes $[74,75]$ and to a mechanical bending [76] (Figure 6b). The non-symmetrical bending motion of the hybrid samples is mainly due to the different size of the cations and anions and, therefore, in the differences in the diffusion of the ions within the PVDF matrix [30]. 
a)

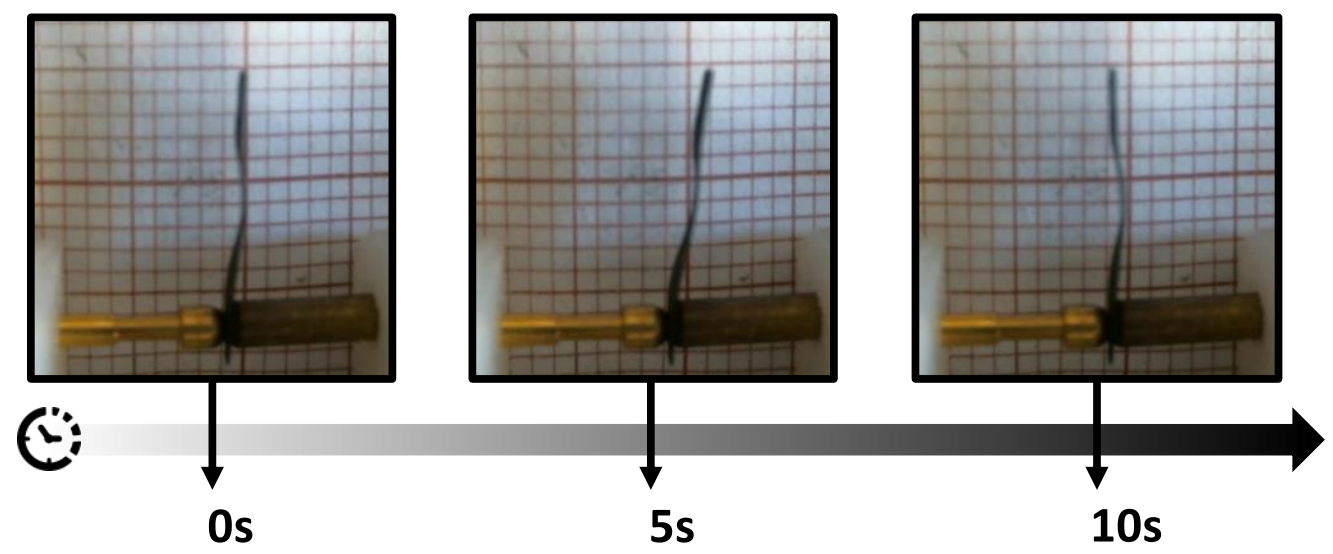

b)

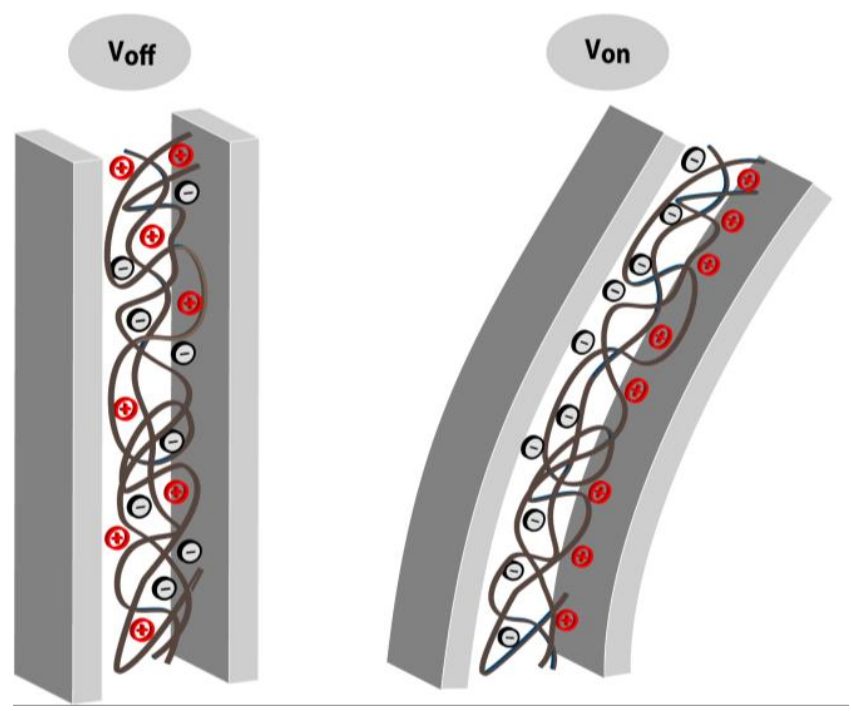

Figure 6. a) Bending upon an applied voltage of $4 \mathrm{~V}$ at a frequency of $100 \mathrm{mHz}$ for the printed $[\mathrm{Bmim}]\left[\mathrm{N}\left(\mathrm{CN}_{2}\right)\right] / \mathrm{PVDF}$ sample (see also supplementary video $\mathrm{S} 1$ ). b) Schematic representation of the ions movement upon the application of an applied voltage.

Theoretical simulations taking into consideration the previous mechanical, ionic and electrical properties of the samples were carried out in order to evaluate the electric field effect in the actuation motion of the composites, the results being shown in figures $5 \mathrm{c}$ ) and $5 \mathrm{~d})$.

The simulated results are in good agreement with the experiments. In Figure 5c), the tip displacement movement being accurately described for the [Bmim][SCN]/PVDF composite. Similar to the $[\mathrm{Bmim}]\left[\mathrm{C}\left(\mathrm{CN}_{3}\right)\right]$ composite, the amplitude of the movement 
for $[$ Bmim $][\mathrm{SCN}] / \mathrm{PVDF}$ composite is accurate (Figure 5d), the model allowing therefore the design of bending actuators by properly selecting material physical parameters [49].

\subsection{Prototype construction}

A potential application of the soft actuators has been demonstrated through the development of a micro gripper for objects with a weights up to $20 \mathrm{mg}$, as represented in Figure 7. For the demonstration, the $[\mathrm{Bmim}]\left[\mathrm{N}\left(\mathrm{CN}_{2}\right] / \mathrm{PVDF}\right.$ sample has been used as no significant differences are observed for both $[\mathrm{Bmim}]\left[\mathrm{N}\left(\mathrm{CN}_{2}\right] / \mathrm{PVDF}\right.$ and [Bmim][SCN]/PVDF sample displacements up to 10 seconds applied signal. As it is shown in Figure 7a, when a voltage of $-5 \mathrm{~V}$ is applied to the $[\mathrm{Bmim}]\left[\mathrm{N}\left(\mathrm{CN}_{2}\right)\right] / \mathrm{PVDF}$ film, the ionic charges (cations and anions) migrate close to the electrodes and a current of $\sim-2.6 \mathrm{~mA}$ is generated (Figure $7 \mathbf{b}$ ).

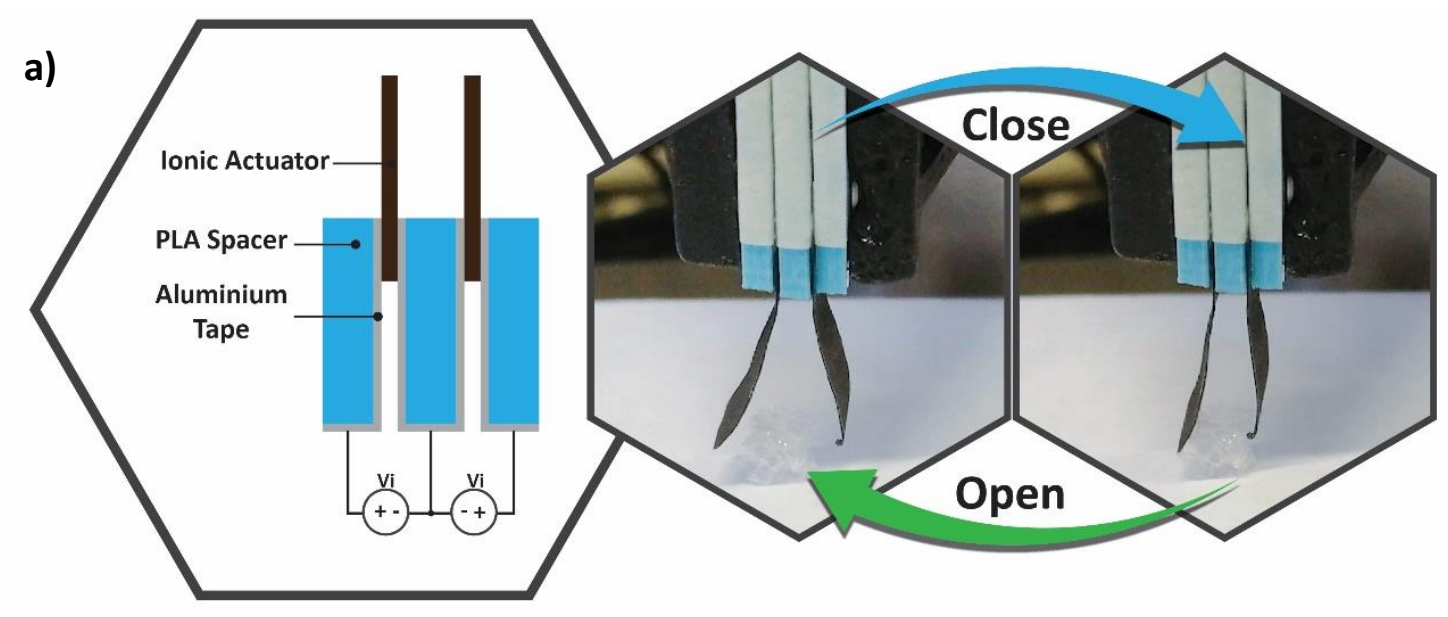

b)

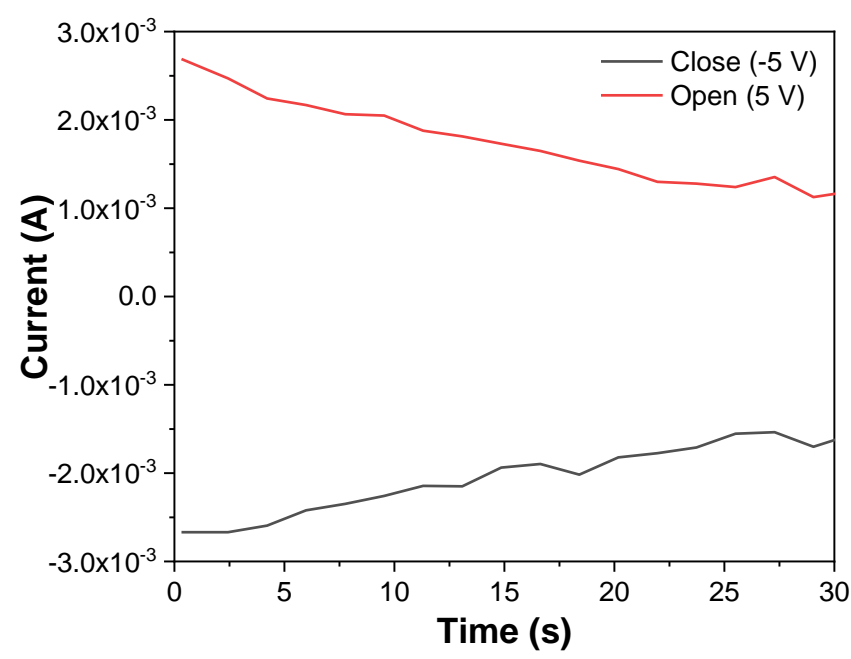


Figure 7. a) $[\mathrm{Bmim}]\left[\mathrm{N}\left(\mathrm{CN}_{2}\right)\right] / \mathrm{PVDF}$ micro gripper actuator (see also supplementary video S2) and b) developed current as a function of time.

At this moment, the micro gripper starts to close. After a few seconds, the current value starts to decrease as a result of the lower sample mobility due to the ionic charges separation leading to the halt of the micro gripper. The same process is observed when a voltage of $5 \mathrm{~V}$ is applied, resulting in an initial current of $2.69 \mathrm{~mA}$ and in the movement of the microgripper to the open position, the process occurring until the ionic charge separation is completed. This movement has been used to grip a plastic cube as demonstrated in the supplementary video S2 and in Figure 7a.

\section{Conclusions}

Printed IL/PVDF films containing ILs sharing the same cation $[\mathrm{Bmim}]^{+}$and different anions were obtained by a direct write ink technique.

For all the printed materials, PVDF crystallizes into the $\beta$ phase due to the low temperature processing and, independently of the anion type, the incorporation of ILs into the PVDF matrix leads to a further increase of the electroactive phase content as a result of the ion-dipole interactions between the IL anions and cations a the PVDF dipoles. A highest $\beta$ phase content of $82 \%$ was observed for [Bmim][SCN]/PVDF sample. For all hybrid samples, a plasticizing mechanical effect is revealed by the decrease of the Young Modulus and tensile strength, which is also accompanied by a decrease of the degree of crystallinity with respect to pristine PVDF. The highest ionic conductivity was developed by the $[\mathrm{Bmim}]\left[\mathrm{N}\left(\mathrm{CN}_{2}\right)\right] / \mathrm{PVDF}$ composite, $5.2 \times 10^{-5} \mathrm{~S} / \mathrm{cm}$, a value six orders of magnitude larger than for PVDF.

The performance of the printed actuators was evaluated by electromechanical measurements in both DC and AC mode. The highest bending displacement was observed for the $[\mathrm{Bmim}][\mathrm{SCN}] / \mathrm{PVDF}$ composite both in AC mode, with a displacement of $1 \mathrm{~mm}$ at an applied voltage of $4 \mathrm{Vpp}$ at a frequency of $100 \mathrm{mHz}$, and in $\mathrm{DC}$ mode at $4 \mathrm{~V}$ being the displacement $4.75 \mathrm{~mm}$ at $60 \mathrm{~s}$. The bending motions was successfully simulated by finite theoretical simulations, based on the mechanical and electrical properties of the 
materials. Finally, a micro gripper was developed demonstrating the suitability of the allprinted soft actuators for applications.

\section{Acknowledgements}

Work supported by the Portuguese Foundation for Science and Technology (FCT) undes strategic funding UID/FIS/04650/2020 and UID/QUI/0686/2020, project PTDC/FISMAC/28157/2017, and grants SFRH/BPD/121526/2016 (D.M.C), SFRH/BD/145345/2019 (LCF), SFRH/BD/131729/2017 (NP), SFRH/BD/140842/2018 (J.C.B.) and SFRH/BPD/112547/2015 (C.M.C.). The authors thank funding by the Spanish State Research Agency (AEI) and the European Regional Development Fund (ERFD) through the project PID2019-106099RB-C43 / AEI / 10.13039/501100011033. The authors also acknowledge funding from the Basque Government Industry and Education Departments under the ELKARTEK, HAZITEK and PIBA (PIBA-2018-06) programs, respectively. Technical and human support provided by SGIker (UPV/EHU, MICINN, GV/EJ, EGEF and ESF) is gratefully acknowledged.

\section{References}

[1] Bikas H, Stavropoulos P, Chryssolouris G. Additive manufacturing methods and modeling approaches: A critical review. The International Journal of Advanced Manufacturing Technology. 2015;83.

[2] Chen L, He Y, Yang Y, Niu S, Ren H. The research status and development trend of additive manufacturing technology. The International Journal of Advanced Manufacturing Technology. 2017;89(9):3651-60.

[3] Caminero MA, Chacón JM, García-Moreno I, Rodríguez GP. Impact damage resistance of 3D printed continuous fibre reinforced thermoplastic composites using fused deposition modelling. Composites Part B: Engineering \$V 148. 2018:93-103.

[4] Dizon JRC, Espera AH, Chen Q, Advincula RC. Mechanical characterization of 3D-printed polymers. Additive Manufacturing. 2018;20:44-67.

[5] Owen D, Hickey J, Cusson A, Ayeni OI, Rhoades J, Deng Y, et al. 3D printing of ceramic components using a customized 3D ceramic printer. Progress in Additive Manufacturing. 2018;3(1):3-9.

[6] Yanko T, Panov S, Sushchyns'ky O, Pylypenko M, Dmytrenko O. Zirconium alloy powders for manufacture of $3 \mathrm{~d}$ printed articles used in nuclear power industry. Voprosy atomnoj nauki i techniki $=$ Pytannja atomnoï nauky $i$ techniky $=$ Problems of atomic science and technology. 2018;1:148-53.

[7] Hitzler L, Alifui-Segbaya F, Williams P, Heine B, Heitzmann M, Hall W, et al. Additive Manufacturing of Cobalt-Based Dental Alloys: Analysis of Microstructure and Physicomechanical Properties. Advances in Materials Science and Engineering. 2018;2018:12 pages. 
[8] DebRoy T, Wei HL, Zuback JS, Mukherjee T, Elmer JW, Milewski JO, et al. Additive manufacturing of metallic components - Process, structure and properties. Progress in Materials Science. 2018;92:112-224.

[9] Hao W, Liu Y, Zhou H, Chen H, Fang D. Preparation and characterization of 3D printed continuous carbon fiber reinforced thermosetting composites. Polymer Testing. 2018;65:2934.

[10] Van Humbeeck J. Additive Manufacturing of Shape Memory Alloys. Shape Memory and Superelasticity. 2018;4(2):309-12.

[11] Yang Y, Chen Y, Wei Y, Li Y. 3D printing of shape memory polymer for functional part fabrication. The International Journal of Advanced Manufacturing Technology. 2015;84.

[12] Wang Y-C, Chen T, Yeh Y-L. Advanced 3D printing technologies for the aircraft industry: a fuzzy systematic approach for assessing the critical factors. The International Journal of Advanced Manufacturing Technology. 2019;105.

[13] Uriondo A, Esperon Miguez M, Perinpanayagam S. The present and future of additive manufacturing in the aerospace sector: A review of important aspects. Proceedings of the Institution of Mechanical Engineers, Part G: Journal of Aerospace Engineering. 2015;229. [14] Manghnani R. An Exploratory Study: The impact of Additive Manufacturing on the Automobile Industry. International Journal of Current Engineering and Technology. 2017;5(2):91-4.

[15] Liu L, Meng Y, Dai X, Chen K, Zhu Y. 3D Printing Complex Egg White Protein Objects: Properties and Optimization. Food and Bioprocess Technology. 2018;12.

[16] Dankar I, Pujola M, El Omar F, Sepulcre F, Haddarah A. Impact of Mechanical and Microstructural Properties of Potato Puree-Food Additive Complexes on Extrusion-Based 3D Printing. Food and Bioprocess Technology. 2018;11.

[17] Norman J, Madurawe RD, Moore CMV, Khan MA, Khairuzzaman A. A new chapter in pharmaceutical manufacturing: 3D-printed drug products. Advanced Drug Delivery Reviews. 2017;108:39-50.

[18] De Mori A, Peña Fernández M, Blunn G, Tozzi G, Roldo M. 3D Printing and Electrospinning of Composite Hydrogels for Cartilage and Bone Tissue Engineering. Polymers. 2018;10(3).

[19] Sakin M, Kiroglu YC. 3D Printing of Buildings: Construction of the Sustainable Houses of the Future by BIM. Energy Procedia. 2017;134:702-11.

[20] Vanderploeg A, Lee S-E, Mamp M. The application of 3D printing technology in the fashion industry. International Journal of Fashion Design, Technology and Education. 2016;10:1-10.

[21] Lee J, Kim H-C, Choi J-W, Lee IH. A review on 3D printed smart devices for 4D printing. International Journal of Precision Engineering and Manufacturing-Green Technology.

2017;4:373-83.

[22] Foo CY, Lim H, Mahdi MA, Wahid M, Ming H. Three-Dimensional Printed Electrode and Its Novel Applications in Electronic Devices. Scientific Reports. 2018;8.

[23] Shahrubudin N, Te Chuan L, Ramlan R. An Overview on 3D Printing Technology:

Technological, Materials, and Applications. 2019;35:1286-96.

[24] Oliveira J, Correia V, Castro H, Martins P, Lanceros-Mendez S. Polymer-based smart materials by printing technologies: Improving application and integration. Additive Manufacturing. 2018;21:269-83.

[25] Bogue R. Smart materials: a review of capabilities and applications. Assembly Automation. 2014;34(1):16-22.

[26] Ahmed M, Billah MM. Smart Material-Actuated Flexible Tendon-Based Snake Robot. International Journal of Advanced Robotic Systems. 2016;13(3):89.

[27] Salazar H, Nunes-Pereira J, Correia DM, Cardoso VF, Gonçalves R, Martins PM, et al. Poly(vinylidene fluoride-hexafluoropropylene)/bayerite composite membranes for efficient arsenic removal from water. Materials Chemistry and Physics. 2016;183:430-8. 
[28] Ribeiro C, Sencadas V, Correia DM, Lanceros-Méndez S. Piezoelectric polymers as biomaterials for tissue engineering applications. Colloids and Surfaces B: Biointerfaces. 2015;136:46-55.

[29] Bar-Cohen Y, Anderson IA. Electroactive polymer (EAP) actuators-background review. Mechanics of Soft Materials. 2019;1(1):5.

[30] Dias JC, Correia DM, Costa CM, Ribeiro C, Maceiras A, Vilas JL, et al. Improved response of ionic liquid-based bending actuators by tailored interaction with the polar fluorinated polymer matrix. Electrochimica Acta. 2019;296:598-607.

[31] Seminara L, Capurro M, Cirillo P, Cannata G, Valle M. Electromechanical characterization of piezoelectric PVDF polymer films for tactile sensors in robotics applications. Sensors and Actuators A: Physical. 2011;169(1):49-58.

[32] Ferreira JCC, Monteiro TS, Lopes AC, Costa CM, Silva MM, Machado AV, et al. Variation of the physicochemical and morphological characteristics of solvent casted poly(vinylidene fluoride) along its binary phase diagram with dimethylformamide. Journal of Non-Crystalline Solids. 2015;412:16-23.

[33] Correia DM, Gonçalves R, Ribeiro C, Sencadas V, Botelho G, Ribelles JLG, et al.

Electrosprayed poly(vinylidene fluoride) microparticles for tissue engineering applications. RSC Advances. 2014;4(62):33013-21.

[34] Ribeiro C, Sencadas V, Ribelles JLG, Lanceros-Méndez S. Influence of Processing Conditions on Polymorphism and Nanofiber Morphology of Electroactive Poly(vinylidene fluoride)

Electrospun Membranes. Soft Materials. 2010;8(3):274-87.

[35] Cardoso V, Correia D, Ribeiro C, Fernandes M, Lanceros-Méndez S. Fluorinated Polymers as Smart Materials for Advanced Biomedical Applications. Polymers. 2018;10:161.

[36] Martins P, Correia DM, Correia V, Lanceros-Mendez S. Polymer-based actuators: back to the future. Physical Chemistry Chemical Physics. 2020;22(27):15163-82.

[37] Watanabe M, Thomas ML, Zhang S, Ueno K, Yasuda T, Dokko K. Application of Ionic Liquids to Energy Storage and Conversion Materials and Devices. Chemical Reviews.

2017;117(10):7190-239.

[38] Ye Y-S, Rick J, Hwang B-J. Ionic liquid polymer electrolytes. Journal of Materials Chemistry A. 2013;1(8):2719-43.

[39] Correia DM, Fernandes LC, Martins PM, García-Astrain C, Costa CM, Reguera J, et al. lonic Liquid-Polymer Composites: A New Platform for Multifunctional

Applications.n/a(n/a):1909736.

[40] Marr PC, Marr AC. Ionic liquid gel materials: applications in green and sustainable chemistry. Green Chemistry. 2016;18(1):105-28.

[41] Dias JC, Martins MS, Ribeiro S, Silva MM, Esperança JMSS, Ribeiro C, et al.

Electromechanical actuators based on poly(vinylidene fluoride) with [N1 $112(\mathrm{OH})][\mathrm{NTf} 2]$ and [C2mim] [C2SO4]. Journal of Materials Science. 2016;51(20):9490-503.

[42] Guo D, Han Y, Huang J, Meng E, Ma L, Zhang H, et al. Hydrophilic Poly(vinylidene Fluoride) Film with Enhanced Inner Channels for Both Water- and Ionic Liquid-Driven lon-Exchange Polymer Metal Composite Actuators. ACS Applied Materials \& Interfaces. 2019;11(2):2386-97. [43] Mejri R, Dias JC, Besbes Hentati S, Botelho G, Esperança JMSS, Costa CM, et al. Imidazolium-based ionic liquid type dependence of the bending response of polymer actuators. European Polymer Journal. 2016;85:445-51.

[44] Correia DM, Barbosa JC, Costa CM, Reis PM, Esperança JMSS, de Zea Bermudez V, et al. Ionic Liquid Cation Size-Dependent Electromechanical Response of Ionic Liquid/Poly(vinylidene fluoride)-Based Soft Actuators. The Journal of Physical Chemistry C. 2019;123(20):12744-52. [45] Imaizumi S, Ohtsuki Y, Yasuda T, Kokubo H, Watanabe M. Printable Polymer Actuators from Ionic Liquid, Soluble Polyimide, and Ubiquitous Carbon Materials. ACS Applied Materials \& Interfaces. 2013;5(13):6307-15. 
[46] Rocha VG, Saiz E, Tirichenko IS, García-Tuñón E. Direct ink writing advances in multimaterial structures for a sustainable future. Journal of Materials Chemistry A.

2020;8(31):15646-57.

[47] Correia D, Barbosa J, Costa C, Reis P, Esperança J, de Zea Bermudez V, et al. Ionic Liquid Cation Size-Dependent Electromechanical Response of Ionic Liquid/Poly (vinylidene fluoride)Based Soft Actuators. The Journal of Physical Chemistry C. 2019;123(20):12744-52.

[48] Martins P, Lopes AC, Lanceros-Mendez S. Electroactive phases of poly(vinylidene fluoride): Determination, processing and applications. Progress in Polymer Science. 2014;39(4):683-706.

[49] Pugal D, Kim KJ, Aabloo A. An explicit physics-based model of ionic polymer-metal composite actuators. Journal of Applied Physics. 2011;110(8):084904.

[50] Kwon K-S, Ng TN. Improving electroactive polymer actuator by tuning ionic liquid concentration. Organic Electronics. 2014;15(1):294-8.

[51] Tripathi AS, Chattopadhyay BP, Das S. Cost-effective fabrication of ionic polymer based artificial muscles for catheter-guidewire maneuvering application. Microsystem Technologies. 2019;25(3):1129-36.

[52] Wallmersperger T, Akle BJ, Leo DJ, Kröplin B. Electrochemical response in ionic polymer transducers: An experimental and theoretical study. Composites Science and Technology. 2008;68(5):1173-80.

[53] Pugal D. Physics Based Model of Ionic Polymer-Metal Composite Electromechanical and Mechanoelectrical Transduction 2012.

[54] Tripathi M, Bobade S, Kumar A. Preparation of polyvinylidene fluoride-cohexafluoropropylene-based polymer gel electrolyte and its performance evaluation for application in EDLCs. Bulletin of Materials Science. 2019;42.

[55] Mejri R, Dias JC, Hentati SB, Martins MS, Costa CM, Lanceros-Mendez S. Effect of anion type in the performance of ionic liquid/poly(vinylidene fluoride) electromechanical actuators. Journal of Non-Crystalline Solids. 2016;453:8-15.

[56] Correia DM, Costa CM, Sabater i Serra R, Gómez Tejedor JA, Teruel Biosca L, de Zea Bermudez $\mathrm{V}$, et al. Molecular relaxation and ionic conductivity of ionic liquids confined in a poly(vinylidene fluoride) polymer matrix: Influence of anion and cation type. Polymer. 2019;171:58-69.

[57] Correia DM, Sabater i Serra R, Gómez Tejedor JA, de Zea Bermudez V, Andrio Balado A, Meseguer-Dueñas JM, et al. Ionic and conformational mobility in poly(vinylidene fluoride)/ionic liquid blends: Dielectric and electrical conductivity behavior. Polymer. 2018;143:164-72.

[58] Zhao J, Lu H, Zhao X, Malyi OI, Peng J, Lu C, et al. Printable Ink Design towards Customizable Miniaturized Energy Storage Devices. ACS Materials Letters. 2020;2(9):1041-56. [59] Liu Z, Wang W, Stadler FJ, Yan Z-C. Rheology of Concentrated Polymer/lonic Liquid Solutions: An Anomalous Plasticizing Effect and a Universality in Nonlinear Shear Rheology. Polymers. 2019;11(5).

[60] Møller PCF, Mewis J, Bonn D. Yield stress and thixotropy: on the difficulty of measuring yield stresses in practice. Soft Matter. 2006;2(4):274-83.

[61] Franchin G, Scanferla P, Zeffiro L, Elsayed H, Baliello A, Giacomello G, et al. Direct ink writing of geopolymeric inks. Journal of the European Ceramic Society. 2017;37(6):2481-9. [62] Steffe JF. Rheological methods in food process engineering. 2nd ed: Freeman Press: Michigan; 1996.

[63] Ribeiro C, Costa CM, Correia DM, Nunes-Pereira J, Oliveira J, Martins P, et al. Electroactive poly(vinylidene fluoride)-based structures for advanced applications. Nature Protocols. 2018;13(4):681-704.

[64] Meira RM, Correia DM, Ribeiro S, Costa P, Gomes AC, Gama FM, et al. lonic-Liquid-Based Electroactive Polymer Composites for Muscle Tissue Engineering. ACS Applied Polymer Materials. 2019;1(10):2649-58. 
[65] Biswas A, Henkel K, Schmeißer D, Mandal D. Comparison of the thermal stability of the $\alpha$, $\beta$ and $\gamma$ phases in poly(vinylidene fluoride) based on in situ thermal Fourier transform infrared spectroscopy. Phase Transitions. 2017;90(12):1205-13.

[66] Kiefer J, Fries J, Leipertz A. Experimental Vibrational Study of Imidazolium-Based Ionic Liquids: Raman and Infrared Spectra of 1-Ethyl-3-methylimidazolium

Bis(Trifluoromethylsulfonyl)imide and 1-Ethyl-3-methylimidazolium Ethylsulfate. Applied Spectroscopy. 2007;61(12):1306-11.

[67] Peñalber CY, Grenoble Z, Baker GA, Baldelli S. Surface characterization of imidazoliumbased ionic liquids with cyano-functionalized anions at the gas-liquid interface using sum frequency generation spectroscopy. Physical Chemistry Chemical Physics. 2012;14(15):512231.

[68] Martins P, Lopes A, Lanceros-Méndez S. Electroactive phases of poly(vinylidene fluoride): Determination, processing and applications. Progress in Polymer Science. 2014;39:683-706. [69] Meira RM, Correia DM, Ribeiro S, Costa P, Gomes AC, Gama FM, et al. lonic-Liquid-Based Electroactive Polymer Composites for Muscle Tissue Engineering. ACS Applied Polymer Materials. 2019.

[70] Botelho G, Lanceros-Mendez S, Goncalves AM, Sencadas V, Rocha JG. Relationship between processing conditions, defects and thermal degradation of poly(vinylidene fluoride) in the beta-phase. Journal of Non-Crystalline Solids. 2008;354(1):72-8.

[71] Cao Y, Chen Y, Sun X, Zhang Z, Mu T. Water sorption in ionic liquids: kinetics, mechanisms and hydrophilicity. Physical Chemistry Chemical Physics. 2012;14(35):12252-62.

[72] Navarro P, Larriba M, Rojo E, García J, Rodríguez F. Thermal Properties of Cyano-Based Ionic Liquids. Journal of Chemical \& Engineering Data. 2013;58(8):2187-93.

[73] Leones R, Costa CM, Machado AV, Esperança JMSS, Silva MM, Lanceros-Méndez S. Development of solid polymer electrolytes based on poly(vinylidene fluoride-trifluoroethylene) and the [N1 $112(\mathrm{OH})][\mathrm{NTf2}$ ] ionic liquid for energy storage applications. Solid State lonics. 2013;253:143-50.

[74] Mejri R, Dias JC, Hentati SB, Botelho G, Esperanca JMSS, Costa CM, et al. Imidazoliumbased ionic liquid type dependence of the bending response of polymer actuators. European Polymer Journal. 2016;85:445-51.

[75] Reizabal A, Correia DM, Costa CM, Perez-Alvarez L, Vilas-Vilela JL, Lanceros-Méndez S. Silk Fibroin Bending Actuators as an Approach Toward Natural Polymer Based Active Materials.

ACS Applied Materials \& Interfaces. 2019;11(33):30197-206.

[76] Correia DM, Fernandes LC, Cruz BDD, Botelho G, de Zea Bermudez V, Lanceros-Méndez S. Development of Poly(I-Lactic Acid)-Based Bending Actuators. Polymers. 2020;12(5):1187. 